\title{
A physico-chemical study for some edible oils properties
}

\author{
Anişoara-Arleziana NEAGU ${ }^{1}$, Irina NIȚ $\breve{A}^{* 1}$, Elisabeta BOTEZ ${ }^{2}$ and Sibel GEACAI ${ }^{1}$ \\ ${ }^{1}$ Department of Chemistry and Chemical Engineering, ,Ovidius” University of Constanta, 124 Mamaia, \\ Constanta 900527,Romania \\ ${ }^{2}$ Department of Food Science, Food Engineering, Aplied Biotechnology, "Dunărea de Jos" University, 111 \\ Domneasca, Galați 800201, Romania
}

\begin{abstract}
In the present paper we have experimentally determined the density, saponification value, iodine value, acid value, peroxide value for four different edible oils: sunflower oil, corn oil, rapeseed oil and peanut oil. Density was determined in the temperature range of $20{ }^{\circ} \mathrm{C}-50{ }^{\circ} \mathrm{C}$, with a 10 degree step increase. The physicochemical properties of the investigated oils were within the requirements of food domain: saponification value varied from 164.84 to $206.45 \mathrm{mg} \mathrm{KOH} / \mathrm{g}$, peroxide value varied from 9.99 to $24.49 \mathrm{mEg} \mathrm{O}_{2} / \mathrm{kg}$ of sample, acid value varied from 0.22 to $3.97 \mathrm{mg} \mathrm{KOH} / \mathrm{g}$, iodine value varied from 94.35 to $102.02 \mathrm{~g} \mathrm{I}_{2} / 100 \mathrm{~g}$ sample, and density varied from 0.9031 to $0.9208 \mathrm{~g} / \mathrm{cm}^{3}$. Based on experimental data, density were correlated with others properties of edible oils. An empirical model was proposed to correlate oil density with iodine value and temperature. The results of the proposed model were compared with a model from literature. The accuracy of the proposed model was very good, the AAD varying in the range of $0.078 \%$ to $0.092 \%$. The proposed model can be recommended for density of vegetable oils evaluation based on their IV, at different temperatures in the range of $20^{\circ} \mathrm{C}$ to $50^{\circ} \mathrm{C}$.
\end{abstract}

Keywords: density, edible oils, physico-chemical properties.

\section{Introduction}

The importance of edible oils in industries such as foods, energy, cosmetics, pharmaceuticals, or lubricants has been well documented. Physicochemical properties of different types of edible oils have been presented in literature [1-4]. Physical properties of vegetable oils depend primarily on composition (and hence on biological origin) and temperature [3].

The estimation of the physico-chemical properties of edible oils is essential in the design of unit processes such as distillation, heat exchangers, reactors and piping. On the other side, physicochemical properties are an important factor that determines the overall quality and stability of a food system. It has been shown that for vegetable oils, density decreases linearly with temperature increasing [5]. Density, saponification value, iodine value, acid value, peroxide value are some of the important characteristics of a vegetable oil.

Macronutrients like proteins, carbohydrates and lipids and micronutrients like vitamins, minerals and antioxidants are the major components of a healty daily diet [6]. Edible oils are an important part of human diet, being used as food or as an ingredient in food products.

In the present paper we have experimentally determined the density, saponification value, iodine value, acid value, peroxide value for four different edible oils: sunflower oil, corn oil, rapeseed oil and peanut oil. The density was determined for temperature ranging from $20{ }^{\circ} \mathrm{C}$ to $50{ }^{\circ} \mathrm{C}$. The aim of this work was to characterize different edible oils and to propose a model for density prediction. The proposed model can be useful for preliminary 
evaluation of density of edible oils based on other oil characteristics, easily accessible to experimental determination.

\section{Experimental}

All reagents used in this study were of analytical grade. The solutions were prepared with distilled water. Four different edible oils were purchased from the local market. Sunflower oil was produced by Bunge Romania S.R.L. Company, Romania, corn oil by S.C. Man Ro S.R.L. Company, Romania, rapeseed oil by Group Auchan Company, France, peanut oil by Group Auchan Company, France.

Some characteristics of the edible oils used in the experiments are presented in Table 1. Sunflower oil, rapeseed oil and peanut oil are refined oils, while corn oil is unrefined.

Table 1. Characteristics of the edible oils used in this study

\begin{tabular}{|l|l|l|l|l|}
\hline Property $^{*}$ & $\begin{array}{l}\text { Sunflower } \\
\text { oil }\end{array}$ & $\begin{array}{l}\text { Corn } \\
\text { oil }\end{array}$ & $\begin{array}{l}\text { Rapeseed } \\
\text { oil }\end{array}$ & $\begin{array}{l}\text { Peanut } \\
\text { oil }\end{array}$ \\
\hline $\begin{array}{l}\text { Saturated fatty } \\
\text { acids }\end{array}$ & $12 \mathrm{~g}$ & $12 \mathrm{~g}$ & $7 \mathrm{~g}$ & $17 \mathrm{~g}$ \\
\hline $\begin{array}{l}\text { Unsaturated } \\
\text { fatty acids }\end{array}$ & $26 \mathrm{~g}$ & $33 \mathrm{~g}$ & $63 \mathrm{~g}$ & $58 \mathrm{~g}$ \\
\hline $\begin{array}{l}\text { Polyunsatura- } \\
\text { ted fatty acids }\end{array}$ & $62 \mathrm{~g}$ & $55 \mathrm{~g}$ & $30 \mathrm{~g}$ & $25 \mathrm{~g}$ \\
\hline
\end{tabular}

as presented by the producers, per $100 \mathrm{~g}$ oil sample

Density, saponification value, iodine value, acid value, peroxide value were experimentally determined.

\section{Density}

Density of the edible oils was measured using an Anton Parr densitimeter DMA 4500 type equipped with a measurement cell based on the " $U$ " vibrating tube method. The uncertainty in density measurements was $\pm 0.0001 \mathrm{~g} / \mathrm{cm}^{3}$. The density was determined for temperature ranging from $20{ }^{\circ} \mathrm{C}$ to 50 ${ }^{\circ} \mathrm{C}$, with a 10 degrees step increase.

\section{Saponification value}

The saponification value (SV) is defined as the weight of potassium hydroxide, in milligrams, needed to saponify one gram of oil. The method for saponification value determination is based on the oil sample saponification by refluxing with a known excess of alcoholic potassium hydroxide solution. The alkali required for saponification is determined by titration of the excess potassium hydroxide with standard hydrochloric acid, in the presence of phenolphthalein as indicator. A corresponding blank reagent is simultaneously prepared.

The saponification value was calculated with the equation:

$S V=\frac{28.055\left(V_{1}-V_{2}\right)}{m}\left(\frac{m g \quad K O H}{g \quad \text { sample }}\right)$

where SV represents saponification value, (mg $\mathrm{KOH} / \mathrm{g}$ sample); $\mathrm{V}_{1}$ - volume of standard hydrochloric acid required for the blank reagent, $(\mathrm{mL}) ; \mathrm{V}_{2}$ - volume of standard hydrochloric acid required for the sample, $(\mathrm{mL}) ; \mathrm{m}$ - weight of the oil sample (g) [6].

\section{Iodine value}

The iodine value (IV) indicates the degree of unsaturation of the oil. It is defined as the number of grams of iodine absorbed by 100 grams of oil.

The iodine value was determined using Hanus method. The oil sample taken into a glass stopper iodine flask, is dissolved in chloroform. The measured volume of Hanus reagent is accurately added and after thorough mixing, it is placed in the dark for exactly one hour. A corresponding blank reagent is simultaneously prepared. At the end of the specified time, the reaction is stopped by adding potassium iodide and diluted with water to prevent loss of the free iodine. The amount of free iodine is determined by titration with sodium thiosulfate using starch as indicator.

The iodine value was calculated with the equation:

$I V=\frac{\left(V_{1}-V_{2}\right) \times 0.01269 \times 100}{m}\left(\frac{g I_{2}}{100 g \text { sample }}\right)$

where IV represents iodine value, $\left(\mathrm{g} \mathrm{I}_{2} / 100 \mathrm{~g}\right.$ sample); 0.01269 - number of grams of iod corresponding to $1 \mathrm{~mL}$ of sodium thiosulfate solution, $(\mathrm{g}) ; \mathrm{V}_{1}$ - volume of sodium thiosulfate 
solution used for the blank reagent, $(\mathrm{mL}) ; \mathrm{V}_{2}$ volume of sodium thiosulfate solution used for the sample, $(\mathrm{mL}) ; \mathrm{m}$ - weight of the oil sample (g) [7].

\section{Acid value}

The acid value (AV) is defined as the number of milligrams of potassium hydroxide required to neutralize the free acids present in one gram of oil. The acid value is determined by direct titration of the oil sample in an alcoholic medium, against standard potassium hydroxide solution, in the presence of phenolphthalein as indicator.

The acid value was calculated with the equation:

$$
A V=\frac{56.1 \times V \times N}{m}\left(\frac{m g \quad \mathrm{KOH}}{g \quad \text { sample }}\right)
$$

where AV represents acid value, (mg $\mathrm{KOH} / \mathrm{g}$ sample); V - volume of standard potassium hydroxide solution, $(\mathrm{mL}) ; \mathrm{N}$ - normality of the potassium hydroxide solution; $\mathrm{m}$ - weight of the oil sample (g) [8].

\section{Peroxide value}

Peroxide value (PV) measures the miliequivalents of oxygen (hydroperoxides) per 1000 gram of oil. The peroxid value is a measure of the concentration of substances that oxidize potassium iodide to iodine. The oil sample taken into a glass stopper iodine flask, is dissolved in chloroform. The measured volume of glacial acetic acid reagent and potassium iodide is accurately added and after thorough mixing, is placed in the dark for exactly fifteen minutes. At the end of the specified time, the mixture is diluted with distilled water to prevent free iodine loss. The amount of free iodine is determined by titration with sodium thiosulfate, using starch as indicator. A corresponding blank reagent is simultaneously prepared.

The peroxide value was calculated with the equation:

$P V=\frac{\left(V_{2}-V_{1}\right) \times N \times 1000}{m}\left(\frac{m E g \quad O_{2}}{K g \quad \text { oil }}\right)$ where $\mathrm{PV}$ - represents peroxide value, $\left(\mathrm{m} \mathrm{Eg} \mathrm{\textrm {O } _ { 2 }} / \mathrm{kg}\right.$ oil); $\mathrm{V}_{1}$ - volume of standard sodium thiosulfate solution used for the blank reagent, $(\mathrm{mL}) ; \mathrm{V}_{2}$ volume of standard sodium thiosulfate solution used for the sample, $(\mathrm{mL}) ; \mathrm{m}$ - weight of the oil sample (g) [9].

\section{Results and Discussions}

The density of sunflower oil, corn oil, rapeseed oil and peanut oil was experimentally determined for temperature ranging from $20{ }^{\circ} \mathrm{C}$ to $50{ }^{\circ} \mathrm{C}$. The density of vegetable oils is dependent on their fatty acid composition, minor components and temperature [10]. The density variation with temperature for the studied oils is presented in Fig.1. It can be observed that peanut oil has the lower density from the studied vegetable oils; the sunflower oil and corn oil have very similar densities. This difference in the density of the oils may be due to the refined and respectively unrefined character of the studied oils.

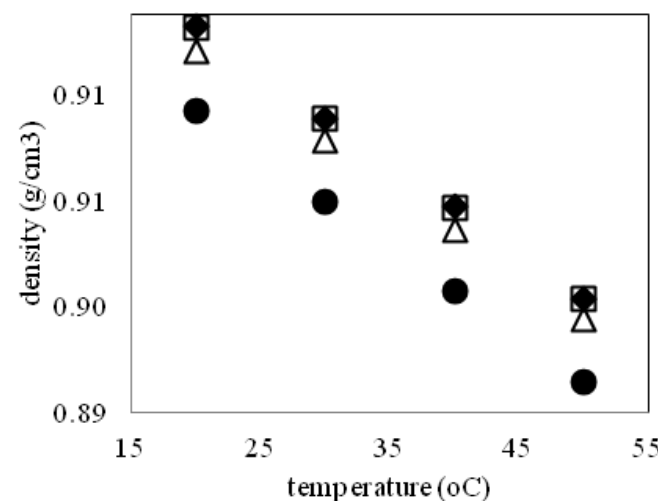

Fig. 1. Vegetable oils density versus temperature ( - sunflower oil; $\square$ - corn oil; $\Delta$ - rapeseed oil; $\bullet$ peanut oil).

As specified in literature [11,12], from fig. 1 it can be observed that the density of vegetable oils linearily decreases with temperature increasing. The rate of density decrease with temperature increasing has been the same for all studied oils.

The experimentally determined values for saponification value, iodine value, acid value and 
peroxid value for the four types of edible oils are presented in Table 2.

Table 2. The physico-chemical properties of edible oils

\begin{tabular}{|c|c|c|c|c|}
\hline Edible oils & $\begin{array}{c}\mathrm{SV} \\
(\mathrm{mg} \\
\mathrm{KOH} / \mathrm{g} \\
\text { sample) }\end{array}$ & $\begin{array}{c}\mathrm{IV} \\
\left(\mathrm{g} \mathrm{I}_{2} / 100\right. \\
\mathrm{g} \mathrm{sample})\end{array}$ & $\begin{array}{c}\mathrm{AV} \\
(\mathrm{mg} \\
\mathrm{KOH} / \mathrm{g} \\
\text { sample })\end{array}$ & $\begin{array}{c}\mathrm{PV} \\
(\mathrm{mEg} \mathrm{O} / \mathrm{kg} \\
\text { sample })\end{array}$ \\
\hline $\begin{array}{c}\text { Sunflower } \\
\text { oil }\end{array}$ & 177.06 & 94.35 & 0.22 & 9.99 \\
\hline Corn oil & 206.49 & 97.35 & 3.97 & 22.49 \\
\hline $\begin{array}{c}\text { Rapeseed } \\
\text { oil }\end{array}$ & 172.29 & 95.12 & 0.62 & 9.99 \\
\hline Peanut oil & 179.83 & 102.02 & 0.39 & 9.99 \\
\hline
\end{tabular}

Saponification value is a measure of oxidation during storage, and also indicates deterioration of the oils. From Table 2 it can be seen that unrefined corn oil has had the highest value of SV, while sunflower oil, rapeseed oil and peanut oil have had SV very close to each other.

The iodine value is an indicator of the degree of unsaturation, a great value of IV indicating an oil prone to oxidation. The unsaturated character affects the stability of oils, and, as a result, leads to the appearance of degradation effects during storage. From the studied oils, the peanut oil is characterized by the greatest IV.

The acid value is a measure of the free fatty acids content of the oil. Since corn oil is unrefined, its AV is higher than the corresponding AV of refined sunflower oil, peanut oil and rapeseed oil, respectively.

Peroxide value is the most common indicator of lipid oxidation. The unrefined vegetable oils are characterized by greater PV values, compared to refined oils. Refined oils used in this study are all characterized by the same value of $\mathrm{PV}, 9.99 \mathrm{mEg}$ $\mathrm{O}_{2} / \mathrm{kg}$ sample (Table 2). The PV of the corn oil is more than two times greater than the PV of the other studied oils (22.49 $\mathrm{mEg} \mathrm{O}_{2} / \mathrm{kg}$ sample).

The physico-chemical properties of the investigated oils were within the requirements of food domain: saponification value varied from 164.84 to $206.45 \mathrm{mg} \mathrm{KOH} / \mathrm{g}$, peroxide value varied from 9.99 to $24.49 \mathrm{mEg} \mathrm{O}_{2} / \mathrm{kg}$ of sample, acid value varied from 0.22 to $3.97 \mathrm{mg} \mathrm{KOH} / \mathrm{g}$, iodine value varied from 94.35 to $102.02 \mathrm{~g} \mathrm{I}_{2} / 100 \mathrm{~g}$ sample, and density varied from 0.9031 to $0.9208 \mathrm{~g} / \mathrm{cm}^{3}[10,13]$.
An empirical equation was proposed in literature to correlate the density of vegetable oils with SV, IV and temperature (Lund equation modified by Pantzaris) [14]:

$d=0.8543+0.000308 \times S V+0.00017 \times I V-0.00068 \times t$

where $\rho$ represents the density of the oil $\left(\mathrm{g} / \mathrm{cm}^{3}\right) ; \mathrm{t}-$ temperature $\left({ }^{\circ} \mathrm{C}\right)$.

An empirical equation was proposed to correlate the density of the studied vegetable oils with IV and temperature:

$$
\rho=a \times t+\frac{b}{I V}
$$

where $\mathrm{a}$ and $\mathrm{b}$ are regression coefficients.

The values of regression coefficients $a$ and $b$ from equation (6) determined based on experimental density results of investigated oils are presented in Table 3.

The accuracy of the proposed model (eq. 6) and of the model from literature (eq.5) was evaluated by the means of absolute average deviation (AAD).

The absolute average deviation was calculated with the equation:

$$
A A D=\frac{100}{n} \times \sum_{i=1}^{n} \frac{\left|\rho_{\text {exp. } i}-\rho_{\text {calc. } i}\right|}{\rho_{\text {exp. } i}}
$$

where $\rho_{\text {exp,i }}$ represents the experimental value of the density; $\rho_{\text {calc,i }}$ - calculated value of the density; $n$ number of experimental points.

Table 3. Regression coefficients for eq. (6)

\begin{tabular}{|c|c|c|}
\hline \multirow{2}{*}{ Edible oil } & \multicolumn{2}{|c|}{ Eq.(6) } \\
\cline { 2 - 3 } & $\mathrm{a}\left(\mathrm{g} / \mathrm{cm}^{3}{ }^{\circ} \mathrm{C}\right)$ & $\mathrm{b}\left(\mathrm{g} / \mathrm{cm}^{3}\right)$ \\
\hline Sunflower & -0.0007 & 87.981 \\
\hline Rapeseed & -0.0007 & 88.537 \\
\hline Peanut & -0.0007 & 94.501 \\
\hline Corn & -0.0007 & 90.779 \\
\hline
\end{tabular}

Figure 2 presents calculated density with equation (5) and equation (6) versus experimental density. 
It can be observed from figure 2 that the density of studied vegetable oils is most accurately estimated with eq.(6), than with eq.(5). Only in the case of peanut oil the results are almost the same.

a) sunflower oil

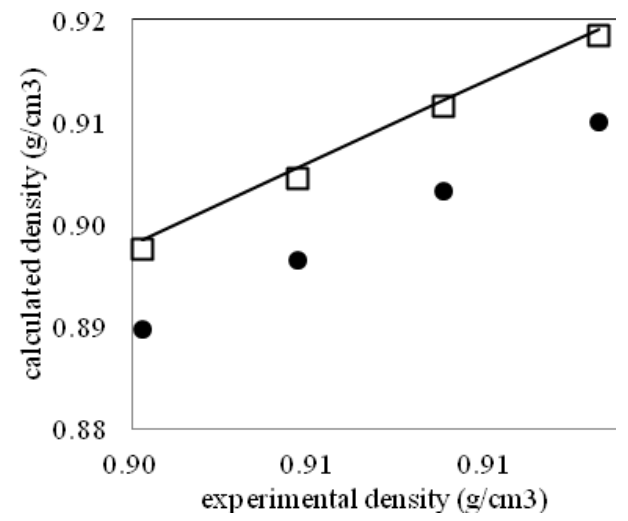

b) corn oil

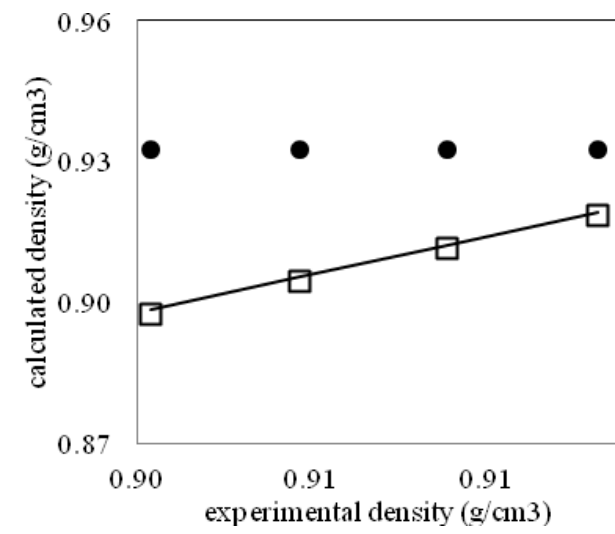

c) rapeseed oil

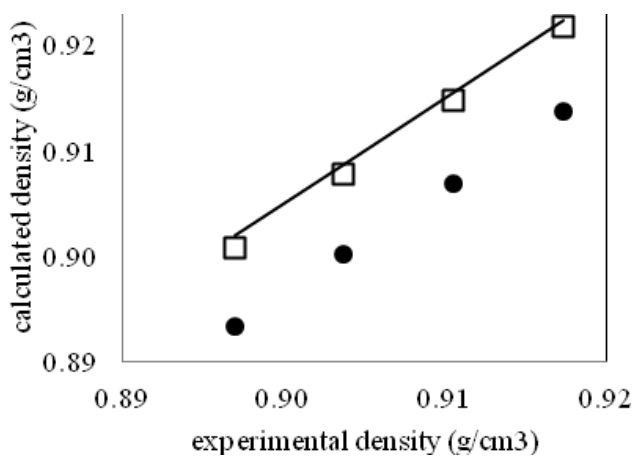

d) peanut oil

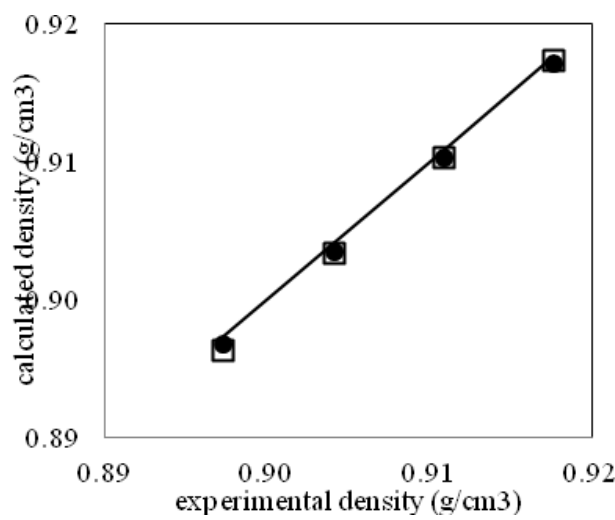

Fig. 2. Calculated density versus experimental density ( $\bullet$ calculated density with eq.(5); calculated density with eq.(6); solid line experimental density)

Equation (5) underestimated the density of sunflower oil and rapeseed oil respectively, and overestimated the density of corn oil.

The accuracy of equation (5) and (6) was evaluated by the means of AAD (\%) (Table 4).

Table 4. The accuracy of density estimation with eq. (5) and eq. (6) (AAD, \%)

\begin{tabular}{|l|l|l|l|l|}
\hline \multirow{2}{*}{} & \multicolumn{4}{|c|}{ Oil type } \\
\cline { 2 - 5 } & sunflower & corn & rapeseed & peanut \\
\hline Eq. (5) & 0.9824 & 2.6256 & 0.9510 & 0.0660 \\
\hline Eq. (6) & 0.0886 & 0.0854 & 0.0920 & 0.0779 \\
\hline
\end{tabular}


The accuracy of the proposed model (eq. 6) for the evaluation of the density of vegetable oils is very good, the AAD varying in the range of $0.078 \%$ to $0.092 \%$. The proposed model can by recommend for density of vegetable oils evaluation based on their IV, at different temperatures in the range of 20 ${ }^{\circ} \mathrm{C}$ to $50{ }^{\circ} \mathrm{C}$.

\section{Conclusions}

Some properties of four types of vegetable oils has been investigated. The physico-chemical properties of the investigated oils were within the requirements of food domain. An empirical equation was proposed to correlate the density of the studied vegetable oils with IV and temperature. The accuracy of the proposed model was very good, the AAD varying in the range of $0.078 \%$ to $0.092 \%$. The proposed model can be recommended for density of vegetable oils evaluation based on their $\mathrm{IV}$, at different temperatures in the range of $20{ }^{\circ} \mathrm{C}$ to $50{ }^{\circ} \mathrm{C}$.

\section{References}

* E-mail address: inita@univ-ovidius.ro

[1]. G. Toscano, G. Riva, E. Poppa and D. Duca, Biomass and Bioenergy 46, 511-516 ( 2012)

[2]. R. D. Gaikwad and P. Swamy, Acta Chim.

Slov., 55, 683 (2008)

[3]. John N. Coupland and D. Julian McClements, J. Am. Oil Chem. Soc.,74, 1559-1564 (1997)

[4]. C. M. Rodenbush, F.H. Hsieh and D.S. Viswanath, J.Am.Oil Chem. Soc., 76 (12), 14151419 (1999)

[5]. B. Esteban, J-R Riba, et al, Biomass Bioenerg, 42, 164-71 (2012)
[6]. *** SR EN ISO 3657:2005

[7]. *** SR EN ISO 3961:2012

[8]. *** SR EN ISO 660:2009

[9]. *** SR EN ISO 3960:2005

[10]. N. A. Fakhri and H. K. Qadir, Journal of Environmental Science and Engineering, 5, 844-849 (2011)

[11]. F. D. Gunstone, Vegetable oils in food technology: Composition, properties and uses, Blackwell Publishing, pp. 41 (2002)

[12]. R. D. Gaiwad and P. Swamy, Acta Chim. Slov., 55, 683-688 (2008)

[13] G. Zhang, Y. Ni, J. Churchill and S. Kokot, Talanta 70, 293-300, (2006)

[14]. F. D. Gunstone, Chemistry of oils and fats: Sources, Composition, Properties and Uses, Blackwell Publishing Ltd., pp.140 (2004)

Submitted: November $5^{\text {th }} 2013$ Accepted in revised form: November $13^{\text {th }} 2013$ 